\title{
Nurses Practice Environment and Quality of Patient Care in Port Said Hospitals
}

\section{Mahran SMA}

Department of Nursing, Port Said University, Egypt

*Corresponding author: Sabah Mahmoud Ahmed Mahran, Department of Nursing, Port Said University, Egypt, Tel: 0663222977, E-mail: dr.sabahmahran@yahoo.com

Received date: December 8, 2016; Accepted date: September 8, 2017; Published date: September 19, 2017

Copyright: (C) 2017 Mahran SMA. This is an open-access article distributed under the terms of the Creative Commons Attribution License, which permits unrestricted use, distribution, and reproduction in any medium, provided the original author and source are credited.

\begin{abstract}
Background: Nurse practice environment has been identified as an important factor in improving the quality and safety of hospital care. However, there are few studies that assess the characteristics of the hospital work environment and its impact on patient outcomes.
\end{abstract}

The aim of the study: To evaluate the characteristics of the nurse's practice environment regarding the quality of patient care as perceived by staff nurses.

Subject and methods: Research design, quantitative design, non-experimental descriptive was utilized.

Setting: This research was carried out in four governmental hospitals in Port Said city. Subjects included (300) of staff nurses who are working at previous hospitals to participate in research study dealing with characteristics of nurse's practice environment regarding the quality of patient care. The tool of data collection: the one tool was used to collect data which aimed to measures eight characteristics of the work environment and quality of patient care.

Results: It revealed that the highest level of agreement score $(75.7 \%)$ for characteristics of the nursing practice environment scale on the unit level was for supportive nurse manager relationships, followed by working with other nurses who are clinically competent while $17.5 \%$ of studied nurses reported agreement regarding support for education in nursing work environment.

Conclusion: There were the means differences between characteristics of practice environment tool and demographic variables as well as quality patient care at units' levels from nurse's perceptions. Overall response mean scores for the nurse was a very high quality of patient care as perceived by staff nurses.

Recommendation: Implement continuous training for nurse's managers about enhancing effective communication by creating an environment which permits to express ideas empower and encourage staff nurses to participate in decision-making and problem-solving process.

Keywords: Nurses practice environment; Quality of care; Patient safety; Job satisfaction

\section{Introduction}

The healthy practice environment is the crucial fact and challenge for the nurse managers and leaders so they have to usually apply frequent assessment for the nursing practice environment to maintain and improve the health of environment [1]. Evaluation of health care in the country tends to focus more on organizational and structural aspects than on empirical outcomes of health care $[2,3]$.

Thus, the vital characteristics of the practice environment were: "working with other competent nurses, good nurse-physician relationships, nurse autonomy and accountability, supportive nurse managers and supervisors, control over nursing practice and work environment, support for education, research and evidence-based practice, adequate nurse staffing and high quality patient care" (American Nurses Credentialing Centre) [4,5].
Additionally, concluded that the most critical components that impacts on the job satisfaction and nurses evaluations of the quality of care provided at the unit level are practice environment and the accessibility of sufficient assets [6,7]. Many problems within the working environment condition include inadequate staffing, providing safe care, long working hours, and a sense of not being valued or involved in decision-making processes concerning patients' problems. These problems lead to nurses leave the profession early in their career [8]

The environment is an impact on the patients, nurses, and organization outcomes where in care is delivered. When nurses are given authority in line with their responsibility, autonomy, and control over patient care resources, they are in a better position to establish positive relationships with physicians. Additionally, nurses can manage the resources as appropriate for meeting patient needs and for communicating problems to the physician in a timely manner [9]. 


\section{Significance of study}

Nurse's practice environment has been associated with the quality of patient care and nurse's satisfaction. So a healthy work environment is important to patients, nurses, nurse managers, and the community at large [10]. Many evidence of literatures provide that the professional work environment create high quality of patient care that attracts and retains nurses in a time of high nurse turnover and low retention rates [9].

The findings of this study might assist the hospital administrators, nurse's leaders, and nurses to initiate strategies for reducing the nursing shortage, increasing the quality of patient care, enhancing of nurses-physician collaboration, attracting and retaining nurses, and promoting health work environment in Egyptian healthcare system.

\section{The research questions}

- What are the characteristics of the nurses practice environment in the Port Said hospitals?

- Is there a relation between nurses practice environment and quality of patient care?

\section{Aim of the study}

Evaluate the characteristics of the nurses practice environment regarding the quality of patient care. This aim was achieved through;

- Identify characteristics of nurse practice environment as perceived by staff nurses.

- Analyse the relation between nurse practice environment and quality of patient care.

\section{Subject and Methods}

\section{Research design}

In this study, the quantitative, non-experimental descriptive design was used to describe the research question and achieve study aim. The researcher decided to use this design to provide detailed information about the characteristics healthy practice work environment for staff nurses.

\section{Setting}

The research was carried out at four governmental hospitals namely; AL- Amery, Al-Nasser, Psychiatric mental health and Port-Fouad. Those hospitals affiliated to Ministry of Health. Also, hospitals provide medical surgical care; maternity and childhood care and Psychiatric and mental health care.

Each hospital has one floor includes gynecology clinics, antenatal unit, delivery and labor unit, operation rooms, postpartum unit, and neonatal intensive care unit except psychiatric and mental health hospital. The researcher decided to conduct this research in Port Said region exactly in governmental hospitals because they provide the healthcare for the majority of the population.

\section{Subjects}

The total target population in this research was (300) staff nurses who are working at above setting. Systematic random sampling technique was used. The researcher calculated the sample size from the whole target population based on the equation used by $n=z^{2} \times p q / d^{2}$ [11].

\section{Tool of data collection}

The data was collected by using a self-administrated questionnaire developed by researcher. It consisted of three parts:

Part [I]: The socio demographic data developed to collect general information's about studied sample. It included age, gender and level of highest education, holding specialty or sub specialty certification, years' experience of staff nurses in nursing and etc).

Part [II]: This part was developed by Aiken and Patrician aimed to measures eight characteristics of a productive and satisfying work environment [12]. This tool consists of 58 questions. It divided into eight essential professional nursing practices characteristics scales; 1 : Collegial/Collaborative RN/MD relationships (6 items). 2: Perceived support for education (4 items). 3: Clinical autonomous decisionmaking (9 items). 4: Control over the context of nursing practice (8 items). 5: Perceived adequacy of staffing (6 items). 6: Working with other nurses who are clinically Competent (4 items). 7: Supportive nurse manager relationship (10 items). 8: Culture in which concern for the patient is paramount (11 items).

Part [III]: It is used to assess the quality of patient care.

\section{Scoring system}

Second part of the tool which measure the characteristics of the practice environment. It is a 4-point Likert scale; the answers were ranging from strongly agree (4 point) to strongly disagree (1 points). Third part of tool measures the quality care scale started by 0 which, mean dangerously low; 5 mean safe but not much more; and 10 mean very high qualities.

\section{Reliability and validity test}

Reliability refers to the stability, consistency and repeatability of data from of instrument over time under identical conditions on different occasions. The researcher used practice work environment scale. It has been tested in many series studied. Coefficient of the NWI$\mathrm{R}$ is 0.96 ; the coefficient for each subscale ranges from 0.75 to 0.79 . In this research, the internal consistency was 0.85 .

The content validity of tool was done by the penal of experts who are professor in specialized nursing administration for the testing the content clarity, sentences understanding \&, time required filling up the tool. The experts finding indicated that the questionnaire was appropriate but it has some challenges in understanding the language used or in measuring the concepts being asked because may some of staff nurses were not familiar with it. Also, the tool was translated from English to Arabic language. The researcher carried out expert's comments.

\section{Pilot study}

The pilot study was carried out for assessing the feasibility of questionnaire, testing the clarity, and determining the time required to fill the tool. The researcher calculated the pilot study subjects based on $10 \%$ of total sample size of the research which equal of 30 registered nurses. It was done over two week's period covering three hospitals. 
Page 3 of 6

\section{Data collection procedure}

After receiving the official permission from the directors of the four hospitals to conduct the study, the researcher conducted meeting with nurse administrators and head nurses in four hospitals for the purpose of providing them information about the study that included the criteria for selection of the staff nurses and determined the methods of distribution in 40 units in four hospitals.

The researcher provided structured questionnaires with a professionally written cover briefly explained the objectives of the study and asking staff nurses to participate with fully awareness of the participation is option in the study and no penalty. The researcher gave 4 weeks period for data collection from $(1 / 3 / 2016)$ to $(31 / 3 / 2016)$.

\section{Data analysis procedures}

Data analyses were performed by using $\left(\mathrm{SPSS}^{\circ}\right)$ version 22 . The data were analysed to determine demographic data and environmental scale to obtain participants percentages and frequency proportions; a mean score and standard deviation for the practice environment scales and subscales to judge which the highest and the lowest means for figuring out the factors that required improvement in current nursing environment and analysis such as bivariate statistical test to the relationships between socio demographic data and practice environment scale by using different statistical test of comparison which includes: Pearson correlations, independent t-test, and Analysis of Variance (ANOVA) test.

\section{Results}

A total studied sample of staff nurses was 300 . The response rate was $100 \%$, there is no any returning questionnaires. Based on the information of socio demographic characteristics of the studied sample, nearly about one third (31.1\%) of studied sample age ranged from 25 to 30 years old. The majority of them $(92.3 \%)$ were females. Maximum of them (93.3\%) had a diploma in nursing. Only (6.7\%) had bachelor of nursing science.

Most of studied sample (92.2\%) had more than 5 years of experience in nursing profession while above half (57.4\%) of them had experience in current hospitals as well as $75.3 \%$ hadn't any plan in staying and serving in current hospitals. In regard to the work pattern shifts in is 12 hours shift or 8 hours shift which is rotated every two weeks on the day, afternoon and night shifts each month in each hospital. Most of studied nurses whose were working as 12 hours shift (80\%).

Moreover (55.4\%) were working in the critical units at mean=2.786 and SD is 0.3203 . Tow third (69.65) of studied sample were agree regarding present of the characteristic of nurse practice environment from staff nurses perception. Table 1 summarized scores mean for scales of characteristics of the nursing practice environment.

The highest level of agreement scores for characteristics of the nursing practice environment scale on the unit level (75.7\%) was for supportive nurse manager relationships, followed by working with other nurses who are clinically competent; and culture in which concern for the patient is paramount.

Perceived adequacy of staffing; collegial/collaborative RN/MD relationships and clinical autonomous decision-making were mild level of agreement among studied nurses. Only $17.5 \%$ of studied nurses reported less present regarding support for education in nursing work environment.

\begin{tabular}{|l|l|l|l|}
\hline Patient quality care & $\begin{array}{l}\text { Point on } \\
\text { indicator }\end{array}$ & Frequency & Percentage \\
\hline Dangerously low & $1.0-4.0$ & 29 & $9.70 \%$ \\
\hline Safe but not much more & $4.0-6.0$ & 17 & $5.70 \%$ \\
\hline Very high quality & $6.0-10.0$ & 254 & $85.30 \%$ \\
\hline Total & - & 300 & $100 \%$ \\
\hline
\end{tabular}

Table 1: Summarized scores on the 8 scales of characteristics of the practice environment as perceived by nurses $(n=300)$.

Regarding outcome variable of the practice environment tool. The frequencies and percentage are presented in table (2) the nurse assessed quality of patient care on the scale with (9.7\%) equating to quality of care is dangerously low.

While 5.7\% responding it is safe but not much more, and (85.6\%) exposing very high quality of care. Over all response mean scores for nurse assessed quality of patient care scores indicated (very high quality) as perceived by staff nurses.

\begin{tabular}{|c|c|c|c|c|}
\hline No & The Characteristics & Mean & Percentage & Ranking \\
\hline 1 & $\begin{array}{l}\text { Collegial/Collaborative } \\
\text { RN/MD relationships }\end{array}$ & 2.691 & $67.20 \%$ & 6 \\
\hline 2 & $\begin{array}{l}\text { Perceived support } \\
\text { education }\end{array}$ & 0.703 & $17.50 \%$ & 8 \\
\hline 3 & $\begin{array}{l}\text { Clinical autonomous decision- } \\
\text { making }\end{array}$ & 2.51 & $62.70 \%$ & 7 \\
\hline 4 & $\begin{array}{l}\text { Control over the context of } \\
\text { nursing practice }\end{array}$ & 2.696 & $67.40 \%$ & 5 \\
\hline 5 & $\begin{array}{l}\text { Perceived adequacy of } \\
\text { staffing }\end{array}$ & 2.786 & $69.60 \%$ & 4 \\
\hline 6 & $\begin{array}{l}\text { Working with other nurses } \\
\text { who are clinically competent }\end{array}$ & 3.018 & $75.46 \%$ & 2 \\
\hline 7 & $\begin{array}{l}\text { Supportive nurse manager } \\
\text { relationships }\end{array}$ & 3.029 & $75.70 \%$ & 1 \\
\hline 8 & $\begin{array}{l}\text { Culture in which concern for } \\
\text { the patient is paramount }\end{array}$ & 3.011 & $75.20 \%$ & 3 \\
\hline
\end{tabular}

Table 2: Assessed quality of patient care at hospitals as perceived by staff nurses $(n=300)$.

Table (3) was statistically significant difference in relationship to age and level of education, control over practice and practice competency at $(\mathrm{p}=0.010)$. While there was no statistically significant difference in staff nurses gender and all characteristics of nurse practice environment except the supportive nurses mangers relationship at $(\mathrm{p}=0.055)$.

Conversely, the level of education reflected no statistically significant difference in the relation to all practice environment characteristics except on the decision making of the nurses at $(\mathrm{p}=0.014)$. Moreover, there were a clear statistical difference in years of 
Page 4 of 6

experience in current hospital and control of nursing practice at $(\mathrm{p}=0.032)$ as well as the organization culture at $(\mathrm{p}=0.039)$ which is concern for the patient is paramount.

However, the desirability of studied nurses in staying and working at hospitals was highly significant to supporting staff education at, clinical autonomous decision making, over nursing practice and supportive nurses manager relationship $(\mathrm{p}=0.028)$. Lastly, the working shifts hours was not statistically significant difference to all nurse's practice environment characteristics except supporting staff education at $(\mathrm{p}=0.017)$. The other independent variables were not significant.

\begin{tabular}{|c|c|c|c|c|c|c|c|}
\hline No & The Characteristics & Age & Gender & Level of education & Years of experience & Staying & Shift \\
\hline 1 & $\begin{array}{l}\text { Collegial/Collaborative } \\
\text { relationships }\end{array}$ & 0.2 & 0.547 & 0.3 & 0.095 & 0.176 & 0.582 \\
\hline 2 & Perceived support for education & $0.032^{*}$ & 0.576 & 0.758 & 0.361 & $0.059^{*}$ & $0.017^{*}$ \\
\hline 3 & $\begin{array}{l}\text { Clinical autonomous decision- } \\
\text { making }\end{array}$ & 0.681 & 0.932 & $0.014^{*}$ & 0.753 & $0.000^{*}$ & 0.878 \\
\hline 4 & $\begin{array}{l}\text { Control over the context of nursing } \\
\text { practice }\end{array}$ & $0.024^{*}$ & 0.564 & 0.733 & $0.032^{*}$ & $0.003^{*}$ & 0.458 \\
\hline 5 & Perceived adequacy of staffing & 0.423 & 0.261 & 0.147 & 0.096 & 0.665 & 0.95 \\
\hline 6 & $\begin{array}{l}\text { Working with other nurses who are } \\
\text { clinically competent }\end{array}$ & $0.010^{*}$ & 0.634 & 0.237 & 0.662 & 0.973 & 0.549 \\
\hline 7 & $\begin{array}{l}\text { Supportive } \\
\text { relationships }\end{array}$ & 0.076 & $0.055^{*}$ & 0.178 & 0.77 & $0.028^{*}$ & 0.227 \\
\hline 8 & $\begin{array}{l}\text { Culture in which concern for the } \\
\text { patient is paramount }\end{array}$ & 0.261 & 0.874 & 0.951 & $0.039^{*}$ & 0.205 & 0.679 \\
\hline
\end{tabular}

Table 3: $P$ value of practice environment and demographic characteristics as perceived by staff nurses $(n=300)$.

Results indicated that there is a significant difference between the practice environment scores and quality care of patients at units from nurses perceptions at hospitals showed in table (4) results found that a medium correlation between practice environment with quality of care at four hospitals with $(\mathrm{r}=0.384, \mathrm{p}=0.000)$.

\begin{tabular}{|l|l|l|l|}
\hline \multicolumn{2}{|l|}{ Statics } & Practice environment & Quality Care \\
\hline \multirow{3}{*}{ EOMII } & Pearson correlation & 1 & $0.384^{* *}$ \\
\cline { 2 - 4 } & Sig (2-tailed) & - & 0 \\
\cline { 2 - 4 } & $\mathrm{N}$ & 300 & 300 \\
\hline \multirow{3}{*}{ Quality Care } & Pearson correlation & $0.384^{* *}$ & 1 \\
\cline { 2 - 5 } & Sig (2-tailed) & 0 & - \\
\cline { 2 - 5 } & $\mathrm{N}$ & 300 & 300 \\
\hline **Correlation is significant at the 0.01 level (2-tailed). & \\
\hline
\end{tabular}

Table 4: Correlation between quality of patient care and essentials of a healthy practice environment.

\section{Discussion}

This study evaluates the characteristics of the nurse practice environment regarding the quality of patient care. The noticeable findings contract with the characteristics of the nursing practice environment on the unit level which highlighted the lowest agreement for these formal 'Nurse-physician relationships', lack of financial assistance and/or paid time off for nurses to attend educational programs, lack of an authority source and shared decision-making before making independent or interdependent decisions with a lot of rules and regulations for any procedure; staff nurse do not have control over nursing practice, policies, issues and standards, no consistently budgeted sufficient of staff nurses positions according to the acuity of patients, and problems are solved by slow action, most of people who are afraid to take risks.

This finding shared with Mosadeghrad highlighted that the importance of cooperation and teamwork among healthcare providers and the ability to effectively communicate and collaborate with other health professionals or institutions as an important component of high-quality healthcare services [13]. Asserted by Van Bogaert found that nurse-physician relationships and nurse management had significant positive associations with job satisfaction [14]. This finding respected by (10) concluded that administration boarding should conduct periodic assessments in order to ensure that a healthy work 
environment is maintained and/or improved [10]. Healthy work environments mutually benefit patients, nurses, nurse managers, health care providers, the health team, administration, the institution and the community at large.

In terms of adequacy of staffing and collegial/collaborative nurses and medical relationships and clinical autonomous decision-making were ranking in the mild positive agreement among studied nurses. This incongruent with Hinno et al. expressed more undesirable emotional state regarding adequacy of staffing, reflected low quality of care will be provided [7]. This finding matching with which articulated by Aiken et al. the burnout is low among staff nurses when hospitals are consistently better work environments [9]. More, lower probabilities of having nurses who were dissatisfied with their jobs and who thought that the quality of care on their unit was only fair or poor and higher likelihoods of having nurses report that their patients were ready for discharge.

In relation to support for education, the study was conducting by Abd-El Salam concluded that nearly two third of studied nurses were dissatisfied with opportunities of advancement in their job, primarily regarding to benefits package, promotion and supervision as well as had a low commitment to the organization [15]. This finding matching with current study was $17.5 \%$ of studied nurses reported less present to support for education in nursing practice environment. This finding on the same line with Yakob who reported that staff nurse's total empowerment scores were relatively low [16]. This result is supported by Laschinger who found that nurses were expressed that strongly disagreement regarding to present of access to empowerment structures in nurse practice environment [17].

The results found that there were statistically significant differences in relationship to demographic characteristics age, level of education, years of experience in current hospital, control over practice and practice competency as well as the organization culture as expressed by studied nurses. While, there was no statistically significant difference in gender and working hours in relation to characteristics of nurse practice environment except the supportive nurse's mangers relationship, matching of Mosadeghrad found that there were several factors have moderating effect on the quality of care as individual factors; organizational factors; environmental factors as well as patients' factors such as socio-demographic variables, attitude, and cooperation while the care provider's subjective attributes, including the priority they give to care, would have a moderating influence on the delivery of care [13].

Regarding to control over practice, in this study the nurses reported that do not have control over nursing practice. This result evidence matches that of Dickens reported that nurse's characterized their work environment by relatively high levels of support, cohesion and managerial control but slightly lower levels of autonomy [18]. Consequently, the influence nurses have and the control they can exert over their practice has been linked to nurse satisfaction. Emphasized that Okada the well training for nurses play a vital role that providing completely prepared to use in some specific condition for immediate action, which implied nurses requested more practical and immediately usable "how-to" information instead of core universal knowledge or skills [19].

In addition, nurses wished to have opportunities to expose different health care systems or environment such as outside of hospitals or countries. In term of quality of patient care, the nurse assessed quality of patient care very high quality as expressed by them. This result on the same line with Kvist found that Staff's evaluations of the quality of work in their respective working units had a clear relationship with experiences of job satisfaction [1]. Those who evaluated the quality of work as excellent also rated their job satisfaction to be the highest in all subscales $(\mathrm{P}<0.0001)$. This finding articulate with Hinno et al. found statistically significant relationships between nurses perceptions of their work environment characteristics and quality of care provided and nurses career plans [7]. When work environment characteristics were evaluated to be better, nurse-assessed quality of care also increased and intentions to leave current job decreased linearly.

Regarding the relation between the practice environment scores and quality care of patients at units from nurse's perceptions at hospitals. The results found that a medium correlation between practice environment with quality of care at four hospitals. This finding supported by Van Bogaert corporates that influence of nurses work environments on patient satisfaction, including staffing levels and nurses own perceptions of the quality of their working environment [14].

Additionally, Tervo-Heikkinen found significant variation reflects the complexity of both patient care and the current nursing work environment in relation to patient safety [20]. Added tangible activities are required for effective development to create patient safety culture as supporting of nurse managers and leaders at all levels and nurse staffing evidence Kvist [1]. Asserted by Mahran and Ibrahim emphasized approximately half of studied nurses expressed that patient safety was very good [21]. Although the critical areas evidenced, the mainstream of the studied sample rated patient safety as "acceptable" or "very good" in the intensive care units.

\section{Conclusion}

The findings of this research concluded that staff nurses ranked work environment characteristics at governmental hospitals at Port Said City as highest characteristics were supportive nurse manager relationships; working with the other nurses who are clinically competent and culture in which concern for the patient is paramount scale. Also there are a statically significant relationship between nurse practice environment and quality of patient care as perceived by staff nurses.

\section{Recommendation}

- Based on the result and to improve the nurse practice environment, the following recommendations should be implemented.

- Continue training for nurse managers about evidence based nursing leadership and evidence based practice.

- Enhance effective communication by creating an environment which permits to express of ideas empower and encourage staff nurses to participate in decision making and problem solving process.

- Encourage of collaboration and teamwork as an important tool for respectable climate and empowerment of nurses.

- Conduct continuous staff development programs for leaders and staff nurses to establish pride in their work and recognition by superiors which enhance healthy work environment.

- Activate strategic plans need to include decentralization of decision-making. 


\section{Acknowledgements}

I wish to express my deepest appreciation and sincere step of the gratitude to everyone who has contributed to this work. In particular I would like to thank all staff nurses who working at four governmental hospitals in Port Said city who so generously offered their cooperation and so willingly provided helping us in collecting data. Also, head of departments for handling and helping in gathering data for this study. This study cannot be completed without their helping.

\section{Administrative and ethical considerations}

The official permission obtained from the administration's (hospital directors) of the four hospitals in Port Said city to start data collection after explanation of the aim of the research. In addition, every staff nurse signed consent form paper which explained the objectives of the research and clarified their right to accept or refuse participation. Privacy and confidentiality are ensured to all participants' data.

\section{References}

1. Kvist T, Mantynen R, Turunen H, Partanen P, Miettinen M, et al. (2013) How magnetic are Finnish hospitals measured by transformational leadership and empirical quality outcomes?. J Nurs Manag 21: 152-164.

2. Teperi J, Porter ME, Vuorenoksa L, Baron J (2009) The finnish health care system: A value-based perspective. Sitra, Helsinki.

3. Tervo-Heikkinen T, Kiviniemi V, Partanen P, Vehvilainen Julkunen $\mathrm{K}$ (2009) Nurse staffing levels and nursing outcomes: A bayesian analysis of finnish-registered nurse survey data. J Nurs Manag 17: 986-993.

4. American Nurses Credentialing Center Magnet Recognition Program. Recognizing Nursing Excellence (2008) Application Manual Silver Spring.

5. Drenkard K, Wolf G, Morgan SH, Floyd J, Mulvey C (2011) In magnet: The next generation: Nurses making the difference. Magnet recognition program: pp 9-22.

6. Van Bogaert P, Clarke S, Roelant E, Meulemans H, Van de Heyning P (2010) Impacts of unit-level nurse practice environment and burnout on nurse-reported outcomes: A multilevel modeling approach. J Clin Nurs 19: 1664-1674.

7. Hinno S, Partanen P, Vehvilainen-Julkunen K (2011) Hospital nurse's work environment, quality of care provided and career plans. Int Nurs Rev 58: 255-262.
8. Hinshaw AS (2008) Navigating the perfect storm: Balancing a culture of safety with workforce challenges. Nurs Res 57: 4-10.

9. Aiken LH, Clarke SP, Sloane DM, Sochalski J, Silber JH (2002) Hospital nurse staffing and patient mortality, nurse burnout, and job dissatisfaction. JAMA 288: 1987-1993.

10. Aboshaiqah AE (2015) Nursing work environment in Saudi Arabia. J Nurs Manag 23: 510-520.

11. Al-Sakkak MA, Al-Nowaiser NA, Al-Khashan HI, Al-Abdrabulnabi AA, Jaber RM (2008) Patient satisfaction with primary health care services. Saudi Med J 29: 432-436.

12. Aiken LH, Patrician PA (2000) Measuring organizational traits of hospitals: the revised nursing work index. Nurs Res 49: 146-153.

13. Mosadeghrad AM (2014) Factors influencing healthcare service quality. Int J Health Policy Manag 3: 77-89.

14. Van Bogaert P, Clarke S, Vermeyen K, Meulemans H, Van de Heyning P (2009) Practice environments and their associations with nurse-reported outcomes in Belgian hospitals: Development and preliminary validation of a Dutch adaptation of the Revised Nursing Work Index. Int J Nurs Stud 46: 55-65.

15. El-salam GA, Ibrahim MM, Mohsen MM, Hassanein SE (2008) Relationship between organizational climate and empowerment of nurses in Menoufiya hospitals, Egypt. East Mediterr Health J 14: 1173-1184.

16. Yakob E (2002) Work empowerment as perceived by nurses and physicians working at national heart institute.

17. Laschinger HK, Finegan J, Shamian J, Wilk P (2001) Impact of structural and psychological empowerment on job strain in nursing work settings: Expanding Kanter's model. J Nurs Adm 31: 260-272.

18. Dickens G, Sugarman P, Roger G (2005 ) Nurse's perceptions of the working environment: a UK independent sector study. J Psychiatr Ment Health Nurs 12: 297-302.

19. Okada Y, Tanida A (2015) Nursing practice, working environment, and educational needs of nurses in socialist republic of vietnam.

20. Tervo-Heikkinen T, Partanen P, Vehvilainen-Julkunen K, Laaksonen, K (2008) Working conditions of finnish registered nurses: A national survey. Vard I Norden 28: 8-17.

21. Mahran MS, El-Azim Ibrahim SA (2016) Patient safety culture and application of medication safety rules as perceived by nurses. Am J Nurs Sci 5: 52-58. 